\title{
Prevalence of premature ovarian insufficiency and its determinants in Iranian populations: Tehran lipid and glucose study
}

\author{
Marzieh Rostami Dovom', Razieh Bidhendi-Yarandi ${ }^{*} \mathbb{0}$, Kazem Mohammad ${ }^{2}$, Maryam Farahmand ${ }^{1}$, \\ Fereidoun Azizi ${ }^{3}$ and Fahimeh Ramezani Tehrani ${ }^{1}$
}

\begin{abstract}
Background: Premature ovarian insufficiency (POI) considered as a concerning health issue for women of reproductive age. In this study we aim to estimate the prevalence of POI and assessing the influential factors.

Methods: Data was obtained from Tehran lipid and glucose study (TLGS). All eligible post-menarcheal female participants of the TLGS, ages 20-65, were recruited $(n=6521)$. Participants were followed for the event of menopause, and age at menopause was recorded. Kaplan Meier analysis was applied to estimate mean and median for age at menopause. Weibull accelerated failure time survival regression model (AFT), was applied to assess influential determinants of POI. Conditional probability approach was used to provide estimation for prevalence of POI.

Results: In this population-based study, the prevalence of $\mathrm{POI}$ (menopause age $<40$ years) and early menopause (menopause age $<45$ years) were estimated $3.5 \%$ and $24.6 \%$, respectively. AFT model showed that in comparison to normal weight women, time to menopause was decreased by -0.09 year $(95 \% \mathrm{Cl}-0.27,-0.01, p=0.023)$ and -0.03 year $(95 \% \mathrm{Cl}-0.05,-0.02, p=0.000)$ in underweight and overweight women, respectively. Moreover, time to natural menopause was increased by 0.12 year $(95 \% \mathrm{Cl} 0.07$ to $0.17, p=0.000)$ in women used oral contraceptives for $>6$ months.

Conclusion: About one quartile of Iranian women experienced menopause at an age less than 45, especially the non-normal weight ones; this high prevalence is a critical public health concerns that needs to be addressed by health policy makers.
\end{abstract}

Keywords: Premature ovarian failure, Premature ovarian insufficiency, Prevalence, Early menopause, Late menopause

\section{Background}

Menopause, a natural transitional process in women's lives, usually occurs between the ages of 49 and 52 years [1]; about $4.2-7.6 \%$ of women experience menopause at ages $<45[2,3]$. Early and late menopause are defined as

\footnotetext{
*Correspondence: razi_bidhendi@yahoo.com

${ }^{1}$ Reproductive Endocrinology Research Center, Research Institute for Endocrine Sciences, Shahid Beheshti University of Medical Sciences, No 24, Shahid Arabi St., Yaman Ave, Velenjak, P.O.Box, 19395-4763 Tehran, Iran

Full list of author information is available at the end of the article
}

menopause at $40-45$ and $>55$ years of age, respectively [4].

These conditions are associated with higher risk of cardiovascular disease, osteoporosis, and breast and endometrial cancers [5-7]. Premature ovarian insufficiency (POI) is defined as the cessation of menstruation along with serum estrogen deficiency and rising follicle-stimulating hormones $(\mathrm{FSH})>40 \mathrm{mIU} / \mathrm{L}$ at age $<40$ [8]. Few studies have reported the prevalence of POI using different approaches; reporting a wide range for its prevalence from 1 to $5.5 \%$ [9-12]. In one approach, researchers included both menopausal and non-menopausal women 
and calculated the prevalence of POI by dividing the number of observed POI in the study population to the total number of married participants [11]. In another approach, participants were restricted to menopausal women [9] and the percentage of women with age at menopause $<40$ was reported as the prevalence of POI; this restriction highly influenced the results and may have led to an increased risk of bias in the reported prevalence. To the best of our knowledge, no study has investigated the prevalence of POI using the first approach in the Iranian general populations. In the present study, we provide an estimation for POI, using data collected in the Tehran Lipid and Glucose Study (TLGS) and explore the risk factors among the general population of Iranian women.

\section{Methods}

\section{Study population}

For purposes of the present study, we used data collected in the Tehran Lipid and Glucose Study (TLGS); a cohort study initiated in 1998 to identify the risk factors for noncommunicable diseases in Tehran urban populations. The detail of this population based study was reported elsewhere [13]. In brief, using a stratified cluster random sampling technique, 15,005 people aged $\geq 3$ years were selected from the urban District 13 of Tehran, the capital of the Islamic Republic of Iran. The cohort members were physically examined every 3 years, and their demographic and anthropometric characteristics (education, marital status, and body mass index), smoking habits and reproductive characteristics (menarcheal age, number of pregnancy, abortions, delivery, contraception, and menopausal status) were assessed by trained interviewers during face-to-face interviews using a valid and reliable questionnaire (Additonal file 1 ). For the purpose of the present study, after excluding women who had reached menopause before initiation of the study $(\mathrm{n}=1370)$, women had experienced non-natural menopause (medication, radiotherapy, surgery) $(\mathrm{n}=600)$; those with uncertainty regarding their menopausal status or those within a transitional period of menopause $(\mathrm{n}=931)$, there were 6521 post-menarcheal participants, ages 20-65, who were recruited for the present study. Menopause was defined according to the World Health Organization classification as a condition of absence of spontaneous menstrual bleeding for $>12$ months for which no other pathologic or physiologic cause could be determined [14]. The time point of 1 year before the 12-month period of no menstrual bleeding was regarded as date of menopause and age at natural menopause (ANM) was calculated based on this time point. POI was defined as menopause before age 40 years.
The study protocol was approved by the Medical Ethics Committee of the Research Institute for Endocrine Sciences of Shahid Beheshti University of Medical Sciences and written informed consent was obtained from all participants.

\section{Statistical study}

Baseline characteristics of the population were illustrated through descriptive statistics, and we calculated mean (SD) for normal and Median (IQR) for non-normal factors. To estimate the prevalence of POI, conditional probability of menopause event by age was used. We categorized age into 5 groups with 5 -year intervals and then estimate the incidence of menopause in each age group, so in this way, cumulative distribution of age at menopause were calculated [15]. We conducted a Weibull accelerated failure time (AFT) survival regression model to investigate factors associated with ANM. AFT is a parametric survival model that regresses the logarithm of the survival time over the factors [16, 17]. Factors explored were included age at menarche, age at marriage, parity, abortion, gravity, history of menstrual cycle irregularity, smoking habits, obesity status and using $\mathrm{OC}$ for more than 6 months. Kaplan-Meier analysis was applied to estimate mean and median for ANM as well. Statistical analysis was done using STATA software (version 10; Stata Corp, College Station, TX, USA).

\section{Results}

The characteristics of the study participants according to their menopausal status at the end of study is presented in Table 1. Mean (SD) age and BMI in menopause and non-menopause group were 56 (8) and 37(10) years, $28.8(5.4)$, and $27.1(6.03) \mathrm{kg} / \mathrm{m} 2$, respectively. Table 2 shows the cumulative distribution of onset of natural menopause in age groups; the prevalence of menopause for women age $<40,45,50$, and 55 years were $3.5 \%$, $24.6 \%, 64.5 \%$ and $88.9 \%$, respectively. In addition, late menopause ( $>55$ years) was estimated approximately $1 \%$ (Table 2, Fig. 1). The mean and median (95\% CI) for ANM using Kaplan-Meier analysis were 50.08 (95\% CI 49.9, 50.3 ) and 51 (95\% CI 50.8, 51.2), respectively. The ageadjusted AFT survival model revealed a significant positive association between OC use ( $>6$ months) and ANM $((0.12$ (95\% CI 0.07 to $0.17, p<=0.001))$; a negative association between BMI -0.001 (95\% CI -0.004 to -0.001 , $p=0.041$ ) and ANM was observed (Table 3). Those with $\mathrm{BMI}<18.5 \mathrm{~kg} / \mathrm{m}^{2}$ and those with $\mathrm{BMI} \geq 25 \mathrm{~kg} / \mathrm{m}^{2}$ had shorter ANM compared to those with BMI 18.5-25 kg/ $\mathrm{m}^{2}$ by -0.09 (95\% CI $\left.-0.27,-0.01, p=0.023\right)$ and -0.03 ( $95 \%$ CI -0.05 to $-0.02, p<0.001$ ), respectively; we found no significant association between all other explored factors with ANM (Table 3). 
Table 1 Characteristics of the study participants according to the menopausal status

\begin{tabular}{|c|c|c|c|}
\hline & \multicolumn{3}{|l|}{ Menopause } \\
\hline & No $(n=4605)$ & Yes $(n=1916)$ & *P-Value \\
\hline Age(yrs.), mean (SD) & $37(10)$ & $56(8)$ & $0.000^{*}$ \\
\hline Age of menarche(yrs.), Median (IQR) & $13(1)$ & $14(1)$ & $0.000^{*}$ \\
\hline No abortion, Median (IQR) & $1(1)$ & $1(1)$ & 0.954 \\
\hline No Birth, Median (IQR) & $2(1)$ & $4(2)$ & $0.000^{*}$ \\
\hline BMI(kg/m2) Median (IQR) & $27.1(6.03)$ & $28.8(5.4)$ & $0.000^{*}$ \\
\hline Menstrual irregularity, (\%) & 35.9 & 24.8 & $0.000^{*}$ \\
\hline OCs > 6 months, (\%) & 27 & 71 & $0.000^{*}$ \\
\hline \multicolumn{4}{|l|}{ Marital status, (\%) } \\
\hline Single & 17 & 3.2 & \\
\hline Married & 79.7 & 30.2 & $0.000^{*}$ \\
\hline Widow/divorced & 3.3 & 66.6 & \\
\hline \multicolumn{4}{|l|}{ Smoking } \\
\hline Daily & 2.9 & 2.9 & \\
\hline Occasionally & 2.5 & 0.8 & $0.000^{*}$ \\
\hline Never & 94.6 & 96.3 & \\
\hline \multicolumn{4}{|l|}{ Education, (\%) } \\
\hline Illiterate & 1.4 & 22.7 & \\
\hline$<5$ years & 14 & 4.6 & \\
\hline$\geq 5$ years & 84.6 & 72.7 & $0.000^{*}$ \\
\hline
\end{tabular}

BMI; body mass index, OC; oral contraceptives

*Obtained from $t$ test for normal distribution, Mann Whitney for non-normal, and chi-squared for categorical variables

Table 2 Cumulative distribution of natural menopause by age group

$\begin{aligned} & \text { Menopause } \\ & \text { No, } \mathbf{n}(\%)\end{aligned} \quad$ Yes, $\mathbf{n}(\%)$

Age group (years)

$\begin{array}{lll}20-25 & 1180(98.3 \%) & 21(1.7 \%) \\ 25-30 & 955(98.8 \%) & 12(1.2 \%) \\ 30-35 & 928(98.0 \%) & 19(2.0 \%) \\ 35-40 & 663(96.5 \%) & 24(3.5 \%)^{*} \\ 40-45 & 608(75.4 \%) & 198(24.6 \%) \\ 45-50 & 201(35.5 \%) & 365(64.5 \%) \\ 50-55 & 62(11.1 \%) & 497(88.9 \%) \\ +55 & 8(1.0 \%) & 780(99.0 \%)\end{array}$

${ }^{*}$ Cumulative prevalence of primary ovarian insufficiency (POI) defined as menopause before age 40 years

\section{Discussion}

In this study, we found that $3.5 \%$ of participants experienced POI, $24.6 \%$ experienced early menopause. Among all those assumed anthropometric and reproductive determinants of age at natural menopause, consumption of $\mathrm{OC}$ for $>6$ months and BMI were influential factors that had significant positive and negative effects on ANM, respectively. The prevalence of POI is
Table3 Results of age-adjusted Weibull accelerated failure time (AFT) survival regression model to explore potential factors associated with age at natural menopause

\begin{tabular}{|c|c|c|}
\hline Factors & $\begin{array}{l}\text { Parametric survival } \\
\text { regression coefficient }(95 \% \mathrm{Cl})\end{array}$ & $p$ Value \\
\hline Age of menarche(years) & $0.00(-0.01,0.01)$ & 0.951 \\
\hline Age at marriage & $-0.09(-0.43,0.23)$ & 0.524 \\
\hline Gravity & $-0.11(-0.46,0.23)$ & 0.506 \\
\hline Number of abortions & $-0.01(-0.02,0.01)$ & 0.405 \\
\hline Parity & $0.00(-0.00,0.01)$ & 0.223 \\
\hline \multicolumn{3}{|l|}{ BMI } \\
\hline Underweight $<18.5$ & $-0.09(-0.27,-0.01)$ & $0.023^{*}$ \\
\hline Overweight/Obese > 25 & $-0.03(-0.05,-0.02)$ & $0.000^{*}$ \\
\hline Normal 18.5-24.9 & Ref & - \\
\hline $\begin{array}{l}\text { Having history of } \\
\text { irregular(yes/no) men- } \\
\text { strual cycle }\end{array}$ & $0.03(-0.01,0.06)$ & 0.135 \\
\hline \multicolumn{3}{|l|}{ Smoking habitus } \\
\hline Daily & $-0.04(-0.10,0.02)$ & 0.205 \\
\hline Occasionally & $0.00(-0.11,0.13)$ & 0.908 \\
\hline Never & - & - \\
\hline OCs > 6 months (yes/no) & $0.12(0.07,0.17)$ & $0.001^{*}$ \\
\hline
\end{tabular}

BMl; body mass index, OC; oral contraceptives

Weibull accelerated failure time survival regression model was run over 3560 non-menopause women who were followed to reach the event

*Significant level at $<0.05$ 


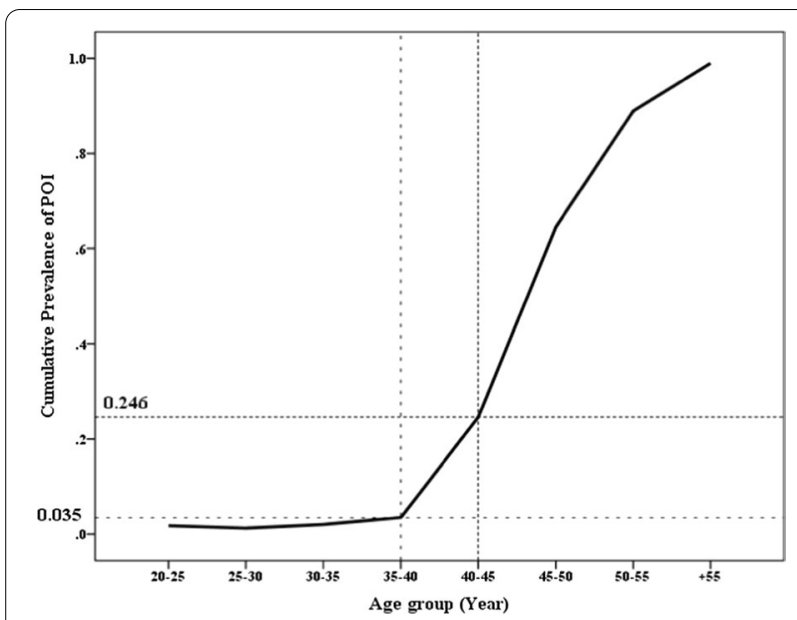

Figure1 Cumulative distribution of age at natural menopause according to age groups

approximately $1 \%$ to $5.5 \%$ worldwide [18]. The differences in the prevalence of natural menopause in the literature could be due to methodological choices. Through a comprehensive systematic literature review, we found that different studies had conducted different approaches to estimate these measures, such as the prevalence of POI. For instance, some of the studies counted the number of POI cases among the total population and estimated the prevalence of POI, leading to underestimated measurements $[2,19]$; other studies, which considered POI cases among natural or natural and medical menopause populations, provided overestimated and also biased measurements [20-38].We used logistic regression to estimate the cumulative prevalence of POI. By this approach, we were able to estimate unbiased estimates of the prevalence $[39,40]$. In addition, the Accelerated Failure Time model was applied to investigate the factors that affected age at menopause. That approach regresses the logarithm of the survival time over the factors and provides a robust parametric model. AFT is very desirable since it is valid under weaker conditions than the Cox proportional hazard model [17]. The novelty of the present study is the methodological approach to POI prevalence estimation with minimal risk of bias in over- or underestimation. Applying the AFT model, we found that OC consumption and BMI were influential determinants of ANM. Contradictory results have been reported regarding the relationship between contraceptive pills and age of menopause [41-44]. In some studies oral contraceptive use were significantly associated with later age at menopause $[41,44]$, while Hassa et al. have no found any association between contraceptive use and age at menopause [42]. We found that those women who used OC for $>6$ months experienced menopause on average one year (obtained from AFT formula model) later than non-users. Our findings concur with De-Vries et al's study [44], which found that each year's use of OC was associated with an increase of 1.2 months of ANM. The main pathophysiologic aspect of this association has not been identified but it may be due to prevention of ovulation. Other studies have not reported this association [43, 45]. In Stanford et al., the association between the use of $\mathrm{OC}$ and age at menopause became non-significant after accounting for the time of exposure. The association between BMI and ANM seems to be nonlinear, as both underweight and overweight women experienced menopause earlier. The women with lower BMI $(<18.5 \mathrm{~kg} / \mathrm{m} 2)$ have poor fat storing that may lead to poor quality of ovarian follicles [46-48]. In contrast to the general perception, lower BMI is unrelated to a decline of estrogen biosynthesis in fatty tissue in lean women, because the onset of estrogen synthesis in peripheral fat happens during postmenopausal time [49]. The association between obesity and ANM may be partly explained through these two hypotheses: (1) In the general population, obesity is associated with hyperinsulinemia, insulin resistance, and steroid hormone binding globulin (SHBG) reduction, which elevates testosterone, dihydrotestosterone, and androstenediol [50]. Decreasing SHBG are related to increasing insulin, glucose, triglycerides, and C-reactive protein, an inflammatory marker in follicular fluid [51]. On the other hand, aging increases insulin resistance and the risk of diabetes type 2 per se. Insulin resistance has a close association with hyperinsulinemia [52]. Moreover, the negative association between the antimullerian hormone (AMH), a valuable marker of ovarian reserve, and Homeostatic Model Assessment for Insulin Resistance (HOMA-IR) levels have been reported [53]. Considering these associations may explain the decline of ANM in overweight/ obese women (2). Ototoxicity of inflammatory factors secreted by adipose tissue may lead to poor quality of oocytes that have been observed in obese mice [54] and humans [55-57]. The relationship between elevated levels of $C$ reactive protein and other oxidative stress factors and impaired oocyte development has been suggested by some studies [51,58]. Theca cells in follicles need insulin for stimulating steroidogenesis and for upregulating luteinizing hormone (LH) receptors expression. Due to hyperinsulinemia in obese women, more receptors will be up regulated and the balance of LH to FSH ratio may disrupted, consequently ovulation and oocyte maturation will be interrupted $[50,59]$. The main strength of our study is its methodology because we used data from a population-based cohort study of non-menopausal women and followed them for about two decades for the event of menopause. Additionally, we used a Weibull accelerated failure time survival regression model that 
is most fitted for data on ANM regarding the flexibility in modeling ANM based on the shape of probability distribution. We also conducted an AFT model to provide a robust inference. The weakness of this study may the recall bias for exact age at menopause, although threeyear's interval for follow-up seems to provide a precise estimation. The absence of FSH measurement is another weakness of this study. Larger longitudinal populationbased studies starting with women in their early reproductive years and following them until menopause are needed for more precise estimation of ANM.

\section{Conclusion}

About one quartile of Iranian women experienced menopause at an age less than 45 , especially the non-normal weight ones; informing the women regarding the negative impact of having abnormal weight throughout the reproductive period, on the age at menopause is recommended.

\section{Supplementary Information}

The online version contains supplementary material available at https://doi. org/10.1186/s12905-021-01228-1.

Additional file 1 (PDF $400 \mathrm{~KB}$ )

\section{Abbreviations}

POl: premature ovarian insufficiency; TLGS: Tehran lipid and glucose study; AFT: accelerated failure time survival regression model; BMl: body mass index; OC: oral contraceptive; ANM: age at natural menopause.

\section{Acknowledgements}

We appreciate the substantial time and effort study participants contributed to this study. Acknowledgments are also due to research staff at the Tehran Lipid and Glucose Study Unit and staff of the Research Endocrine Laboratory.

\section{Authors' contributions}

MRD, RBY, and KM: Substantial contributions to the conception or design of the work, interpretation of data and drafting the work, RBY: Substantial contributions to the conception or design of the work, analysis, interpretation of data for the work, and revising manuscript critically for important intellectual content, and final approval of the version to be published, MF: the acquisition of data, FA: the conception and design of the work, interpretation of data, revising manuscript critically for important intellectual content, final approval of the version to be published, FRT: Revising manuscript critically for important intellectual content, final approval of the version to be published, and agreement to be accountable for all aspects of the work in ensuring that questions related to the accuracy or integrity of any part of the work are appropriately investigated and resolved. All authors read and approved the final manuscript.

\section{Funding}

No funding was obtained for this study.

\section{Availability of data and materials}

The dataset used and analyzed during the current study are available from the corresponding authors upon making official request.

\section{Ethics approval and consent to participate}

This study has been approved by the ethics committee of The Endocrine Research Institute (IR.SBMU.ENDOCRINE.REC.1396.550), and written informed consent was obtained from all individual participants included in the study.
All procedures performed in studies involving human participants were in accordance with the ethical standards of the institutional and/or national research committee and with the 1964 Helsinki declaration and its later amendments or comparable ethical standards. The Medical Ethics Committee of the Research Institute for Endocrine Sciences of Shahid Beheshti University of Medical Sciences granted permission to our team to access the clinical/ personal patient data used in our research.

\section{Consent for publication}

This manuscript does not report personal data such as individual details, images or videos; therefore, consent for publication is not applicable.

\section{Competing interests}

The authors declare that they have no conflict of interest.

\section{Author details}

${ }_{1}^{1}$ Reproductive Endocrinology Research Center, Research Institute for Endocrine Sciences, Shahid Beheshti University of Medical Sciences, No 24, Shahid Arabi St., Yaman Ave, Velenjak, P.O.Box, 19395-4763 Tehran, Iran. ${ }^{2}$ Department of Epidemiology and Biostatistics, School of Public Health, Tehran University of Medical Sciences, Tehran, Iran. ${ }^{3}$ Endocrine Research Center, Research Institute for Endocrine Sciences, Shahid Beheshti University of Medical Sciences, Tehran, Iran.

Received: 22 January 2020 Accepted: 17 February 2021

Published online: 23 February 2021

\section{References}

1. Morabia A, Costanza MC, Neoplasia WHOCSo, Contraceptives S. International variability in ages at menarche, first livebirth, and menopause. Am J Epidemiol. 1998; 148(12):1195-205.

2. Luborsky JL, Meyer P, Sowers M, Gold EB, Santoro N. Premature menopause in a multi-ethnic population study of the menopause transition. Hum Reprod. 2003;18(1):199-206.

3. Mishra GD, Pandeya N, Dobson AJ, Chung HF, Anderson D, Kuh D, et al. Early menarche, nulliparity and the risk for premature and early natural menopause. Hum Reprod (Oxford, Engl). 2017;32(3):679-86.

4. Shifren JL, Gass ML, Group NRfCCoMWW. The North American Menopause Society recommendations for clinical care of midlife women. Menopause. 2014; 21(10):1038-62.

5. Uygur D, Sengul O, Bayar D, Erdinc S, Batioglu S, Mollamahmutoglu L. Bone loss in young women with premature ovarian failure. Arch Gynecol Obstet. 2005;273(1):17-9.

6. RoetersvanLennep JE, Heida KY, Bots ML, Hoek A. Cardiovascular disease risk in women with premature ovarian insufficiency: a systematic review and meta-analysis. Eur J Prev Cardiol. 2016;23(2):178-86.

7. Surakasula A, Nagarjunapu GC, Raghavaiah KV. A comparative study of pre- and postmenopausal breast cancer: risk factors, presentation, characteristics and management. J Res Pharmacy Pract. 2014;3(1):12-8.

8. Santoro N. Mechanisms of premature ovarian failure. Ann Endocrinol. 2003;64(2):87-92.

9. Progetto Menopausa Italia Study G. Premature ovarian failure: frequency and risk factors among women attending a network of menopause clinics in Italy. BJOG 2003; 110(1):59-63.

10. Coulam CB, Adamson SC, Annegers JF. Incidence of premature ovarian failure. Obstet Gynecol. 1986;67(4):604-6.

11. Jungari SB, Chauhan BG. Prevalence and determinants of premature menopause among indian women: issues and challenges ahead. Health Soc Work. 2017;42(2):79-86.

12. Beck-Peccoz P, Persani L. Premature ovarian failure. Orphanet J Rare Dis. 2006;1:9.

13. Azizi F, Madjid M, Rahmani M, Emami H, Mirmiran P, Hadjipour R. Tehran lipid and glucose study (TLGS): rationale and design. Iran J Endocrinol Metab. 2000;2(2):77-86

14. World Health Organization. Research on the Menopause in the 1990s: Report of a WHO Scientific Group. Geneva: World Health Organization; 1996: 12-14. WHO Technical Report Series No. 866.

15. Bidhendi Yarandi R, Rostami-Dovom M, Mohammad K, Ramezani Tehrani F. To the Editor. Menopause (New York, NY). 2020; Publish Ahead of Print. 
16. Kalbfleisch JD, Prentice RL. The statistical analysis of failure time data. New York: Wiley; 2011.

17. Wei L-J. The accelerated failure time model: a useful alternative to the Cox regression model in survival analysis. Stat Med. 1992;11(14-15):1871-9.

18. Golezar S, Ramezani Tehrani F, Khazaei S, Ebadi A, Keshavarz Z. The global prevalence of primary ovarian insufficiency and early menopause: a meta-analysis. Climacteric. 2019;22(4):403-11.

19. Shamsa DS, Al Hashimi BA. Onset of natural menopause and factors affecting its development: a study from primary health care centres in Al-Risafa in Baghdad. Iraqi New Med J. 2017;3:17-26.

20. Mondul AM, Rodriguez C, Jacobs EJ, Calle EE. Age at natural menopause and cause-specific mortality. Am J Epidemiol. 2005;162(11):1089-97.

21. Adamopoulos DA, Karamertzanis M, Thomopoulos A, Pappa A, Koukkou E, Nicopoulou SC. Age at menopause and prevalence of its different types in contemporary Greek women. Menopause (New York, NY). 2002:9(6):443-8.

22. Sullivan SD, Lehman A, Nathan NK, Thomson CA, Howard BV. Age of menopause and fracture risk in post-menopausal women randomized to calcium + Vitamin D, hormone therapy, or the combination: results from the Women's Health Initiative Clinical Trials. Menopause (New York, NY). 2017;24(4):371.

23. Hong JS, Yi S-W, Kang HC, Jee SH, Kang HG, Bayasgalan G, et al. Age at menopause and cause-specific mortality in South Korean women: Kangwha Cohort Study. Maturitas. 2007;56(4):411-9.

24. Brand JS, Van Der Schouw YT, Onland-Moret NC, Sharp SJ, Ong KK, Khaw K-T, et al. Age at menopause, reproductive life span, and type 2 diabetes risk: results from the EPIC-InterAct study. Diabetes Care. 2013;36(4):1012-9.

25. Jacobsen BK, Knutsen SF, Fraser GE. Age at natural menopause and total mortality and mortality from ischemic heart disease: the Adventist Health Study. J Clin Epidemiol. 1999;52(4):303-7.

26. Li S, Rosenberg L, Wise LA, Boggs DA, LaValley M, Palmer JR. Age at natural menopause in relation to all-cause and cause-specific mortality in a follow-up study of US black women. Maturitas. 2013;75(3):246-52.

27. Muka T, Asllanaj E, Avazverdi N, Jaspers L, Stringa N, Milic J, et al. Age at natural menopause and risk of type 2 diabetes: a prospective cohort study. Diabetologia. 2017;60(10):1951-60.

28. Group PMIS, article lopiateot. Premature ovarian failure: frequency and risk factors among women attending a network of menopause clinics in Italy. BJOG. 2003; 110(1):59-63.

29. Rödström K, Bengtsson C, Lissner L, Björkelund C. Reproducibility of self-reported menopause age at the 24-year follow-up of a population study of women in Göteborg, Sweden. Menopause (New York, NY). 2005;12(3):275-80.

30. Yahya S, Rehan N. Age, pattern and symptoms of menopause among rural women of Lahore. J Ayub Med Coll Abbottabad. 2002; 14(3).

31. Anolue FC, Dike E, Adogu P, Ebirim C. Women's experience of menopause in rural communities in Orlu, Eastern Nigeria. Int J Gynecol Obstet. 2012;118(1):31-3.

32. Jacobsen BK, Heuch I, Kvåle G. Age at natural menopause and stroke mortality: cohort study with 3561 stroke deaths during 37-year follow-up. Stroke. 2004; 35(7):1548-51.

33. Choi SH, Lee S-M, Kim Y, Choi N-K, Cho YJ, Park B-J. Natural menopause and risk of stroke in elderly women. J Korean Med Sci. 2005;20(6):1053-8.

34. Rahman I, Åkesson A, Wolk A. Relationship between age at natural menopause and risk of heart failure. Menopause (New York, NY). 2015:22(1):12-6.

35. Ryan J, Scali J, Carriere I, Amieva H, Rouaud O, Berr C, et al. Impact of a premature menopause on cognitive function in later life. BJOG. 2014;121(13):1729-39.

36. Amagai Y, Ishikawa S, Gotoh T, Kayaba K, Nakamura Y, Kajii E. Age at menopause and mortality in Japan: the Jichi Medical School cohort study. J Epidemiol. 2006;16(4):161-6.

37. Cooper GS, Sandler DP. Age at natural menopause and mortality. Ann Epidemiol. 1998;8(4):229-35.

38. Bansal P, Chaudhary A, Soni R, Gupta VK. Epidemiological determinants of age at natural menopause in rural women of Punjab. J Res Med Den Sci. 2014;2(1):24-8
39. Mohammad K, Hashemi SMS, Farahani FKA. Age at natural menopause in Iran. Maturitas. 2004;49(4):321-6.

40. Parsaeian M, Pouraram H, Djazayery A, Abdollahi Z, Dorosty A, Jalali M, et al. An explanation for variation in age at menopause in developing countries based on the second national integrated micronutrient survey in Iran. Arch Iran Med (AIM). 2017; 20(6).

41. Gold EB, Crawford SL, Avis NE, Crandall CJ, Matthews KA, Waetjen LE, et al. Factors related to age at natural menopause: longitudinal analyses from SWAN. Am J Epidemiol. 2013:178(1):70-83.

42. de Vries E, den Tonkelaar I, van Noord PA, van der Schouw YT, te Velde ER, Peeters PH. Oral contraceptive use in relation to age at menopause in the DOM cohort. Hum Reprod (Oxford, Engl). 2001;16(8):1657-62.

43. Hassa H, Tanir HM, Tekin B, Senses T, Oge T, Mutlu FS. Possible factors affecting the age at menopause among women in the central anatolian region of Turkey. Clin Exp Obstet Gynecol. 2006;33(1):59-60.

44. Gold EB, Bromberger J, Crawford S, Samuels S, Greendale GA, Harlow SD, et al. Factors associated with age at natural menopause in a multiethnic sample of midlife women. Am J Epidemiol. 2001;153(9):865-74.

45. Stanford JL, Hartge P, Brinton LA, Hoover RN, Brookmeyer R. Factors influencing the age at natural menopause. J Chronic Dis. 1987:40(11):995-1002.

46. Zhu D, Chung HF, Pandeya N, Dobson AJ, Kuh D, Crawford SL, et al. Body mass index and age at natural menopause: an international pooled analysis of 11 prospective studies. Eur J Epidemiol. 2018;33(8):699-710.

47. Hardy R, Mishra GD, Kuh D. Body mass index trajectories and age at menopause in a British birth cohort. Maturitas. 2008;59(4):304-14.

48. Akahoshi M, Soda M, Nakashima E, Tominaga T, Ichimaru S, Seto S, et al. The effects of body mass index on age at menopause. Int J Obes Relat Metab Disorders. 2002;26(7):961-8.

49. Tao X, Jiang A, Yin L, Li Y, Tao F, Hu H. Body mass index and age at natural menopause: a meta-analysis. Menopause (New York, NY). 2015;22(4):469-74.

50. Brewer $\mathrm{CJ}$, Balen $\mathrm{AH}$. The adverse effects of obesity on conception and implantation. Reprod (Cambridge, England). 2010;140(3):347-64.

51. Robker RL, Akison LK, Bennett BD, Thrupp PN, Chura LR, Russell DL, et al. Obese women exhibit differences in ovarian metabolites, hormones, and gene expression compared with moderate weight women. J Clin Endocrinol Metab. 2009:94(5):1533-40.

52. Weyer C, Funahashi T, Tanaka S, Hotta K, Matsuzawa Y, Pratley RE, et al. Hypoadiponectinemia in obesity and type 2 diabetes: close association with insulin resistance and hyperinsulinemia. J Clin Endocrinol Metab. 2001:86(5):1930-5.

53. Park HT, Cho GJ, Ahn KH, Shin JH, Kim YT, Hur JY, et al. Association of insulin resistance with anti-Mullerian hormone levels in women without polycystic ovary syndrome (PCOS). Clin Endocrinol. 2010;72(1):26-31.

54. Hou Y-J, Zhu C-C, Duan X, Liu H-L, Wang Q, Sun S-C. Both diet and gene mutation induced obesity affect oocyte quality in mice. Sci Rep. 2016;6:18858.

55. Cardozo E, Pavone ME, Hirshfeld-Cytron JE. Metabolic syndrome and oocyte quality. Trends Endocrinol Metab: TEM. 2011;22(3):103-9.

56. Robker RL. Evidence that obesity alters the quality of oocytes and embryos. Pathophysiology. 2008;15(2):115-21.

57. Purcell SH, Moley KH. The impact of obesity on egg quality. J Assist Reprod Genet. 2011;28(6):517-24.

58. Agarwal A, Gupta S, Sharma RK. Role of oxidative stress in female reproduction. Reprod Biol Endocrinol RB\&E. 2005;3:28.

59. Jain A, Polotsky AJ, Rochester D, Berga SL, Loucks T, Zeitlian G, et al. Pulsatile luteinizing hormone amplitude and progesterone metabolite excretion are reduced in obese women. J Clin Endocrinol Metab. 2007:92(7):2468-73.

\section{Publisher's Note}

Springer Nature remains neutral with regard to jurisdictional claims in published maps and institutional affiliations. 